\title{
Intestinal fatty acid digestion and energy utilization in lambs infused with different plant oils into the abomasum
}

\author{
T Obitsu, $\mathrm{H}$ leki, K Taniguchi
}

Faculty of Applied Biological Science, Hiroshima University, Higashihiroshima-shi 724, Japan

Protected fat escaping ruminal degradation is regarded as a useful additive for the increase of energy supply. However, fat sources entering the small intestine may affect intestinal fatty acid digestion and nutrient utilization in host animal. The objective of this study was to investigate the effects of different plant oils infused into the abomasum on intestinal fatty acid digestion and energy utilization in lambs.

Three male lambs (initial body weight : $26.6 \pm 2.1 \mathrm{~kg}$ ) fitted with abomasal and ileal cannulae were used in a $3 \times 3$ Latin square design. Lambs were fed a basal diet ( $40 \%$ hay and $60 \%$ concentrate) at 1.6 times maintenance energy level. Emulsified coconut oil (CO), palm oil (PO) or rice bran oil (RO) with Cr-EDTA was continuously infused into the abomasum for 17 days of each period. The daily amount of fat infusion was $5 \%(\mathrm{w} / \mathrm{w})$ of the basal diet ( $2.5 \mathrm{~g} / \mathrm{BW} 0.75$ day). As a control, the lambs were fed the basal diet with abomasal infusion of soy lecithin (an emulsifying regent) for 17 days before the Latin square. lleal digesta, feces, urine and venous blood were collected during the last 6 days of each period. Ileal digesta flow was calculated by the indicator method. Fatty acid contents in ileal digesta and feces were measured by GLC after direct methylation (Sukhija and Palmquist, 1988, J Agric Food Chem, 36, 1202-1206). Heat production over 24 hours was measured by indirect calorimetry.

Gross energy intake (GE) tended to be lower for $\mathrm{CO}$ and $\mathrm{PO}$ than for control and RO due to the decreases in dry matter intakes. Energy digestibility (DE/GE) tended to be higher for $\mathrm{CO}$ than for PO. Heat production (HP) was not affected by fat infusion and fat sources. Energy retention to metabolizable energy (ER/ME) was higher for RO than for other three treatments. Total fatty acids (TFA) entering the ileum were variable, but fecal TFA excretion was lower for $\mathrm{CO}$ than for PO. Intestinal digestibility of infused TFA was $97.4,86.8$ and $93.7 \%$ for $\mathrm{CO}, \mathrm{PO}$ and $\mathrm{RO}$, respectively. Plasma concentrations of triglycerides and nonesterified fatty acids tended to increase with fat infusion. Plasma total cholesterol was higher for $\mathrm{CO}$ and $\mathrm{PO}$ than for control.

These results indicated that energy of RO infused into the abomasum may be used more efficiently than that $\mathrm{CO}$ and $\mathrm{PO}$ in growing lambs.

\begin{tabular}{|c|c|c|c|c|c|}
\hline Item & Control & $\mathrm{CO}$ & $\mathrm{PO}$ & RO & SEM \\
\hline \multicolumn{6}{|l|}{ GE (kJ/kg0.75) } \\
\hline Basal diet & 1121 & 977 & 969 & 1051 & 26 \\
\hline Basal diet + oil & 1121 & 1092 & 1091 & 1175 & 26 \\
\hline DE/GE (\%) & 78.5 & 81.6 & 78.0 & 79.3 & 0.8 \\
\hline ME (kJ/kg $\left.{ }^{0.75}\right)$ & $745^{a b}$ & 764ab & $736^{a}$ & $804^{b}$ & 6 \\
\hline $\mathrm{HP}\left(\mathrm{kJ} / \mathrm{kg}^{0.75}\right)$ & 534 & 544 & 516 & 526 & 6 \\
\hline$E R\left(k J / k^{0.75}\right)$ & $212^{a}$ & $220^{a}$ & $220^{a}$ & $278^{b}$ & 3 \\
\hline ER/ME (\%) & $28.4^{\mathrm{a}}$ & $28.8^{\mathrm{ab}}$ & $29.7^{\mathrm{ab}}$ & $34.5^{b}$ & 0.5 \\
\hline \multicolumn{6}{|l|}{ Total fatty acid flow } \\
\hline Ileum (mg/kgo.75) & 277 & 130 & 718 & 392 & 85 \\
\hline Feces $\left(\mathrm{mg} / \mathrm{kg}^{0.75}\right)$ & $200^{a}$ & $243^{a}$ & 509 & $341^{\mathrm{ab}}$ & 24 \\
\hline
\end{tabular}

$a, b: P<0.05$. 